\title{
Wicket Spikes: Clinical Correlates of a Previously Undescribed EEG Pattern
}

\author{
JEAN REIHER, AND MICHEL LEBEL
}

SUMMARY: From an analysis of the electroencephalograms of 4,458 patients who underwent recording during both wakefulness and sleep, through the years 1969 to 1975, wicket spikes - recorded in 39 patients - may be described as follows:

They were found during both wakefulness and sleep, almost exclusively in adults. Their cardinal feature is a changing mode of occurrence through any single recording: from intermittent trains , of more or less sustained, arciform, dis-

RÉSUMÉ: Sur un total de 4,458 malades adressés à notre laboratoire entre 1969 et 1975 pour un enregistrement à l'état de veille et de sommeil, des pointes arciformes ont été recueillies chez 39 sujets.

Les pointes arciformes se reconnaissent aux caractéristiques suivantes: elles se retrouv'ent tant à l'état de veille que pendant le sommeil, et, presque exclusivement chez l'adulte. Fait singulier, elles surviennent uniformément, dans chaque cas, tantôt en trains constitués de décharges soutenues, plus ou moins prolongées, ressemblant alors au rhythme mu; tantôt de façon isolée, pouvant donner alors le change pour des charges resembling mu rhythm, to sporadic, unitary, single spikes. When occurring singly, wicket spikes can be mistaken for anterior or middle temporal spikes, since they predominate in either area, and since they share with them other characteristics such as amplitude (60 to 210 microvolts), polarity (surface negative) duration, and configuration.

Wicket spikes should not be considered interictal abnormalities; they do not correlate with epilepsy or with any particular symptom complex.

pointes temporales antérieures ou moyennes; de ces dernières, dont elles partagent d'autres constantes telles amplitude, durée, polarité et localisation, les pointes arciformes ne se distinguent que par leur distribution temporelle.

La distinction entre pointes arciformes et pointes temporales n'en demeure pas moins capitale; car contrairement aux pointes temporales antérieures et moyennes, elles n'ont rien d'une anomalie inter-critique; aucune corrélation n'a pu en effet être retenue entre pointes arciformes et épilepsie, qu'elle soit généralisée ou partielle, temporale ou extra-temporale.
From the Department of Neurology, Centre Hospitalier Universitaire, Sherbrooke, Quebec, Canada.

Reprint requests to: Dr. Jean Reiher, Centre Hospitalier Universitaire, Sherbrooke, Quebec, J1H 5N4 Canada.

Read before the meeting of the Canadian Congress of Neurological Sciences, Winnipeg, October 13-16, 1976.
The purpose of this study is to outline the electroencephalographic characteristics and the clinical correlates of wicket spikes. If mistakes in the assessment and management of patients referred to an EEG laboratory are to be avoided, it is important to differentiate these patterns from other recognizable patterns, and from anterior and middle temporal spikes in particular.

\section{MATERIAL}

The electroencephalograms of all patients recorded while awake and asleep in our laboratory through the years 1969 to 1975 were reviewed. Of a total of 4,458 patients, only 39 showed wicket spikes in sufficient number to allow for detailed analysis.

The description which follows rests upon an analysis of the 129 EEG traces obtained in these 39 patients, and a review of their clinical records.

\section{RESULTS}

Wicket spikes were found during wakefulness and sleep. During wakefulness they could be masked by neighboring rhythms. They were more easily recognized during sleep. From the first seconds of drowsiness, as alpha and mu rhythms subsided, wicket spikes emerged. Seldom encountered during deep sleep, wicket spikes were most abundant during the first three stages of sleep. They were detected during REM sleep in the only patient whose recording was carried on through that stage. Wicket spikes tended to occur in longer trains during wakefulness and drowsiness, and in shorter groups of 2 to 4 seconds duration 


\section{WICKET SPIKES}

\section{- TraW-}

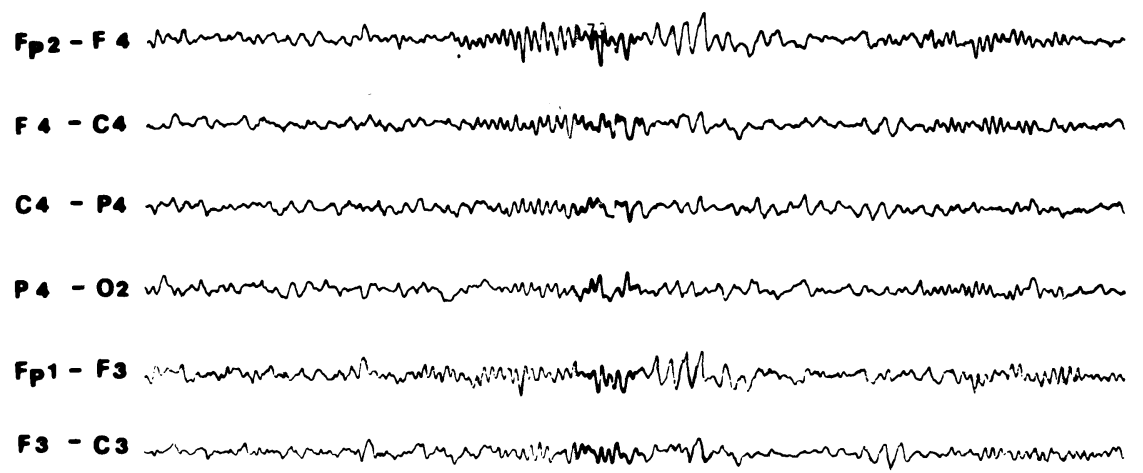

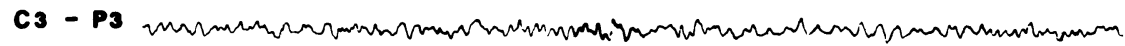

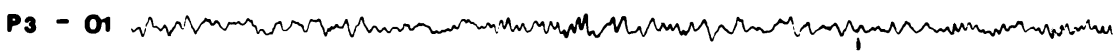

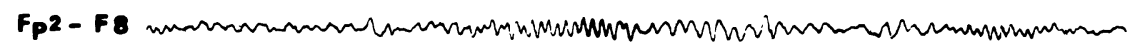

F 8 - T4

T4 - T6

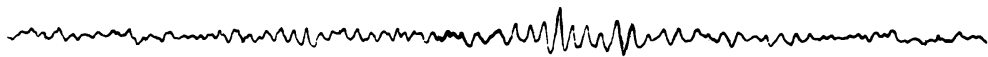

T6 - 02

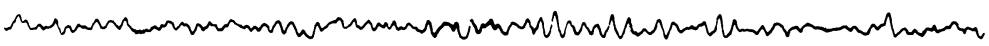

FP1 - F7 2

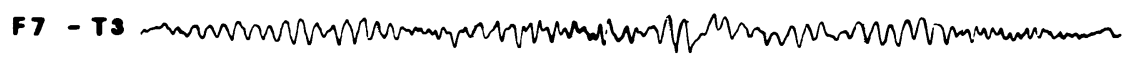

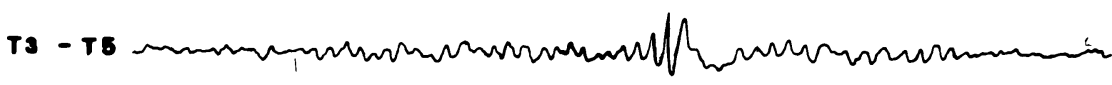

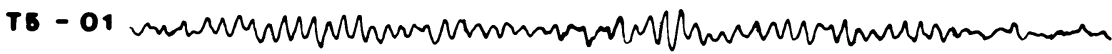

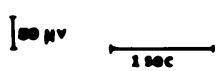

Figure 1-Patient asleep; trains of bitemporal wicket spikes, more prominent on the left side.

during sleep. Under those conditions; they could seldom be mistaken for spikes (Figure 1, 2). Frequently, however, wicket spikes stood out as single spikes (Figures $3,4)$.

They were uniformly recorded over both temporal regions, independently on either side, usually with a one-sided predominance. Their precise distribution varied between patients and frequently even in the same patient. They usually predominated in either middle or an- terior temporal area spreading to the ipsilateral ear. Occasionally, they were recorded maximally from the inferior or posterior temporal regions. They spread a little to parasagittal regions, and then more so to the frontal regions.

The amplitude of wicket spikes varied from 60 to 210 microvolts. The amplitude was less when they occurred in trains than when they appeared singly. They were surface negative and essentially monophasic. Their frequency, rang- ing from 6 to $11 \mathrm{~Hz}$, varied through any single trace and even within the same burst.

Wicket spikes were recorded almost exclusively in adults; 37 out of the 39 patients were 30 years of age or older; the youngest was aged 13 years and the eldest 81 years. Their overall incidence in our laboratory population was $0.9 \%$.

The majority of patients -31 out of 39 - was referred because of a wide variety of conditions other than epileptic seizures, as can be seen in Table I. In only eight patients was the diagnosis of epilepsy established. Of these, five had, in addition to wicket spikes in their EEGs, abnormalities such as anterior temporal spikes (in three) and spike and wave complexes (in two). Neurological examination was unremarkable except for the one patient with residuals of an infantile hemiplegia. In this retrospective study, detailed systematic psychometric evaluation was not carried out.

Skull X-Rays were obtained in 24 patients, and brain scans in 9; they were all normal. Echoencephalograms were normal in 29 out of 33 patients; of the remaining 4, the midline echo was shifted significantly in the only patient with an infantile left hemiplegia (a shift of $6 \mathrm{~mm}$ toward the right side). Angiography or pneumoencephalography was not carried out in any of the patients.

\section{COMMENTS}

It is difficult to differentiate middle and anterior temporal spikes from wicket spikes, especially when wicket spikes occur singly (Figure 4). Similarities in polarity, localization, and amplitude may be striking (Figure 7,8). Of the various parameters of wicket spikes, the cardinal one is the changing mode of occurrence throughout any single recording; from intermittent trains of more or less sustained, prolonged, arciform discharges resembling the wicket rhythm - more properly called the mu rhythm - to sporadic, unitary, isolated spikes. Recognition of the breakdown of trains and clusters of wicket spikes to their simplest form, the isolated wicket spike, 
TABLE I

Clinical Diagnosis and Associated EEG Findings in 39 Patients with Wicket Spikes

Number of Patients

EEG Findings

(wake and sleep)

NON-EPILEPTICS (31)

Syncope .

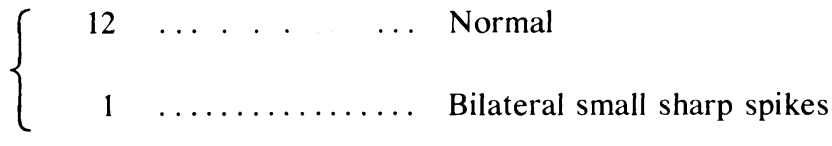

Anxiety reaction, hyperventilation syndrome $\ldots .$.

10

1

Tension headache

Benign positional vertigo

Tic douloureux ...

Delirium Tremens

Transient global amnesia

Infantile hemiplegia

\section{EPILEPTICS (8)}

Petit Mal and Grand Mal

Complex partial seizures with occasional generalized seizures

Probably secondarily generalized tonico-clonic seizures

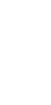

2

1

1

1

1

1

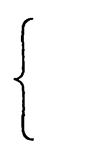

1

1

\{
2
Normal

6/s. spike and wave complexes

Normal

Bilateral small sharp spikes

Normal

Normal

Normal

Normal

$3 c / s$ spike and wave complexes

Atypical spike and wave complexes

Normal

Left temporal spike focus;

bilateral small sharp spikes

Left temporal spike focus

Right temporal spike focus

Normal

TABLE II

Incidence of Wicket Spikes in Two Selected Groups of Patients

\begin{tabular}{|c|c|c|c|c|}
\hline & $\begin{array}{c}\text { Number of } \\
\text { Patients }\end{array}$ & $\begin{array}{c}\text { Patients in whom } \\
\text { Clinical Diagnosis } \\
\text { of Epilepsy } \\
\text { was Made }\end{array}$ & $\begin{array}{c}\text { Number of } \\
\text { Patients with } \\
\text { Wicket Spikes }\end{array}$ & $\begin{array}{c}\text { Incidence of } \\
\text { Wicket Spikes }\end{array}$ \\
\hline Group I & 100 & 100 & 1 & $1 \%$ \\
\hline Group II & 100 & 0 & 3 & $3 \%$ \\
\hline
\end{tabular}

is mandatory for proper interpretation. Trains and clusters invariably precede isolated spikes; so much so that the eventual emergence of isolated wicket spikes can be predicted, and should be expected to occur once the first trains and clusters have been identified in a recording.

The appelation of wicket spikes even though antithetic, has the merit of conveying not only its configuration - wicketed, or "en arceau" but also its changing mode of occurrence.

Wicket spikes are not as common as other patterns, such as small sharp spikes and 14 and 6/second positive spikes (Reiher and Klass, 1968). Their overall incidence $0.9 \%$ - slightly higher than that of psychomotor variant (Gibbs et al., 


\section{WICKET SPIKES} Quster

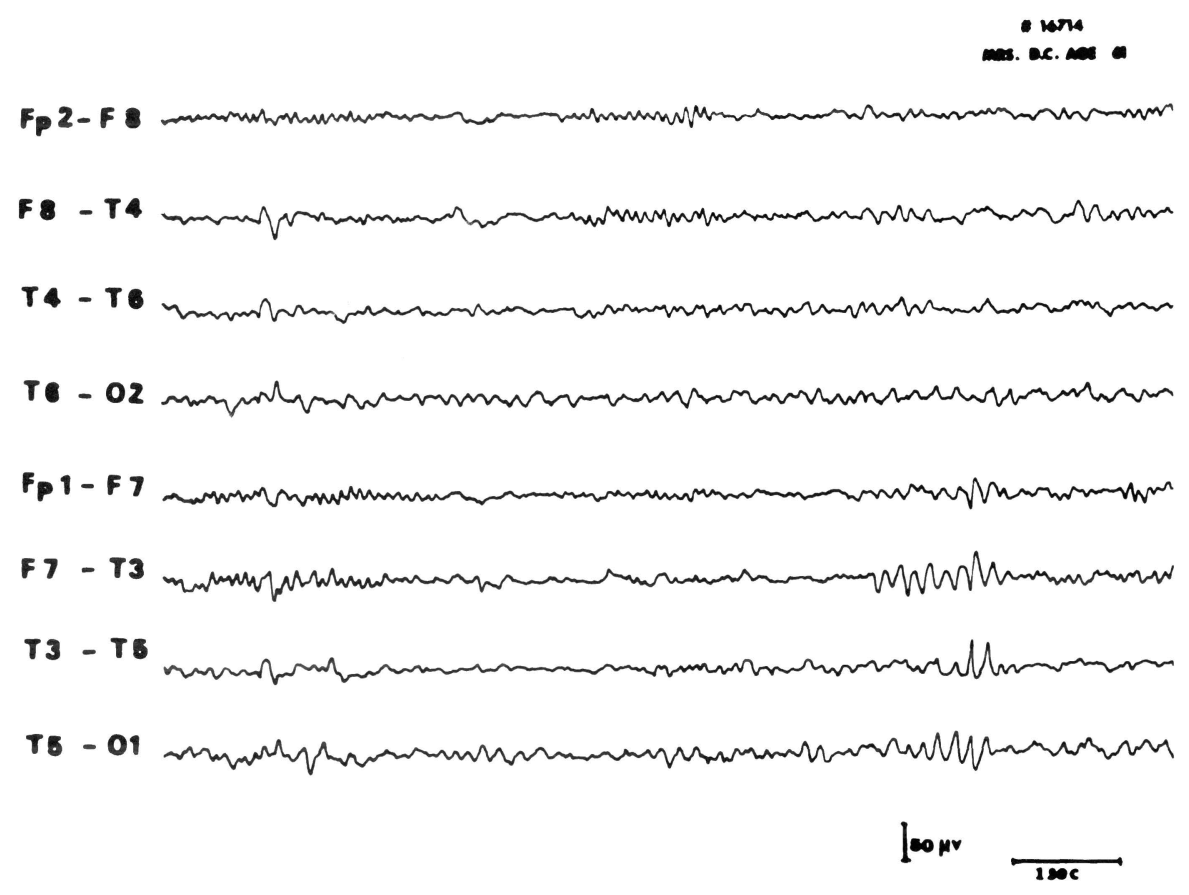

Figure 2-Patient asleep; wicket spikes occurring in clusters over the left temporal region.

\section{WICKET SPIKES}

-OUTSTANONG TRANSENT AMIOST QUSTER-

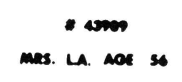

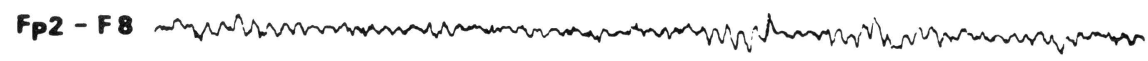

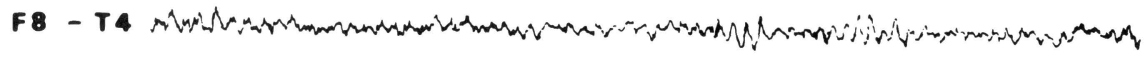

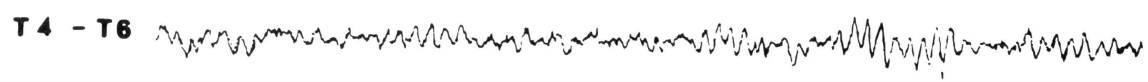

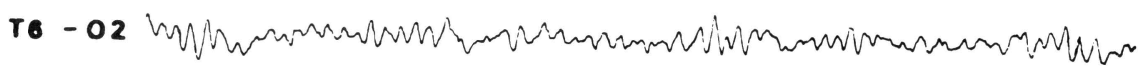

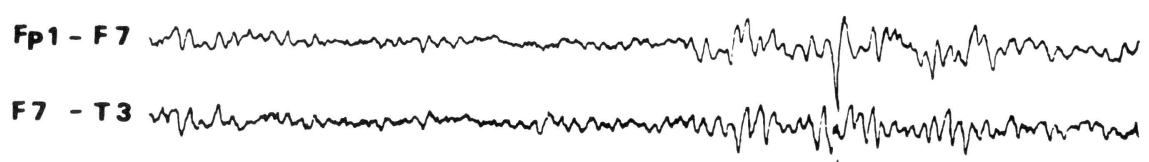

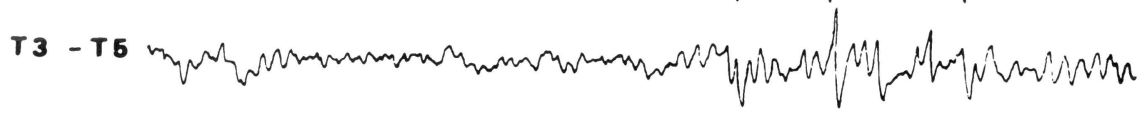

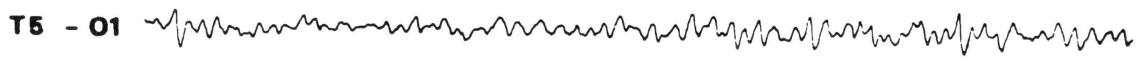

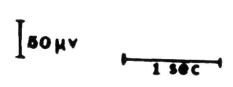

Figure 3-Train of wicket spikes with an outstanding one predominating at $\mathrm{F}_{7}$ and $\mathrm{T}_{3}$.
1963) would have barely doubled, had patients with only occasional wicket spikes in their records been included in the study. In patients above the age of 30 , however, their incidence rose to $2.9 \%$. Wicket spikes can be differentiated from the 6/second positive spikes (Figure 5) and from the psychomotor variant of Gibbs (1963) (Figure 6) by their polarity, morphology, preferential spread to the frontal areas, and by their changing frequency and amplitude.

Whereas anterior and middle temporal spikes almost invariably represent interictal abnormalities (Gibbs and Gibbs, 1952; Lombroso, 1967) found in the EEG of patients with partial seizures, our preliminary observations lead us to believe that wicket spikes do not correlate with epilepsy. Wicket spikes were encountered in patients without a history of seizures four times more frequently than in those with a history (Table I). Furthermore, as Table I suggests, should wicket spikes be a specific pattern in those 8 patients with a history of seizures, they would represent an unlikely interictal pattern in patients with seizures generalized from the onset, as well as in patients with partial seizures.

To verify the reliability of these preliminary observations, we decided to review electroencephalograms and clinical charts of two groups of patients, matched for age, and all seen by neurologists at a time when interest in the wicket spike pattern had not developed in our institution. Because of the increasing prevalence of the pattern with age, only patients above the age of 30 were included in this subsequent study. The data are summarised in Table II. Group I consisted of 100 consecutive patients who presented either with generalized seizures, or with partial seizures of temporal or extra-temporal lobe origin. Group II consisted of 100 consecutive patients who presented with a variety of conditions other than seizures. It can be seen that:

1. The incidence of wicket spikes is not significantly different in the two groups: $1 \%$ in the group 
TABLE III -

Frequency of Wicket Spikes Among Three Groups of Patients

\begin{tabular}{|l|c|c|c|}
\hline & General Population & Epileptics & Non-Epileptics \\
\hline $\begin{array}{l}\text { Number of patients with } \\
\text { wicket spikes }\end{array}$ & 37 & 1 & 3 \\
Total number of patients & 1266 & 100 & 100 \\
$\%$ & 2.92 & 1.00 & 3.00 \\
\hline $\mathrm{X}_{1}^{2} \quad(1$ vs 2$)=1.27 ; \quad \mathrm{p}=0.26 ;$ not significant \\
$\mathrm{X}_{1}^{2} \quad(1$ vs 3$)=0.002 ; \quad \mathrm{p}=0.96 ;$ not significant \\
$\mathrm{X}_{1}^{2}(2$ vs 3$)=1.03 ; \quad \mathrm{p}=0.31 ;$ not significant \\
\hline $\mathrm{X}_{2}^{2}(1$ vs 2 vs 3$)=1.276 ;=\mathrm{p}=0.53$ \\
Test of Homogeneity
\end{tabular}

\section{WICKET SPIKES}

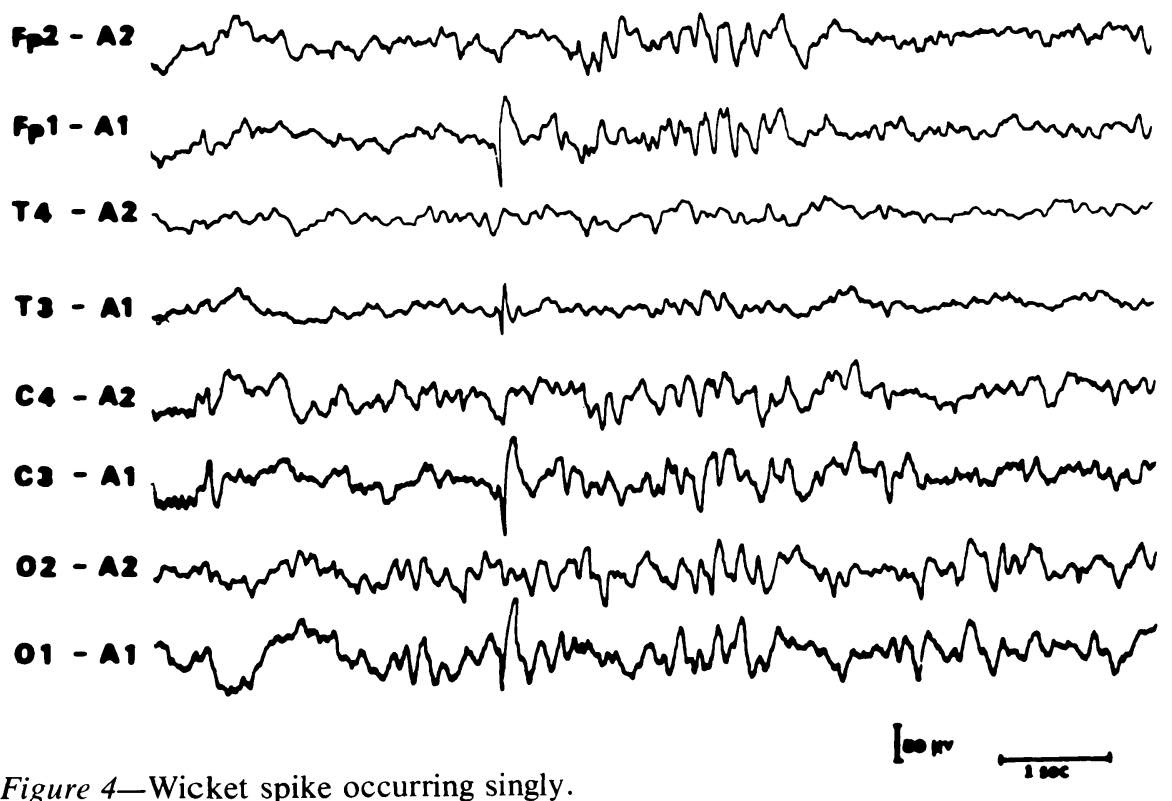

Figure 4-Wicket spike occurring singly.

of epileptic patients, and $3 \%$ in the group of non-epileptic patients.

2. The incidence of wicket spikes in both selected groups of patients is not significantly different from that found $(2.9 \%)$ in the general population of our laboratory for the same age group (Table III).

It would seem reasonable to conclude that, contrary to anterior and middle temporal spikes, wicket spikes should not be regarded as interictal abnormalities. Whether wicket spikes represent an abnormality at all needs to be investigated further. Their incidence in a controlled asymptomatic population needs to be assessed. Finally, from the data available in our 39 patients, it may be tentatively concluded that demonstrable involvement of temporal lobe structures cannot be inferred from the presence of bitemporal wicket spikes.

Even though the diagnosis of epilepsy rests primarily on clinical grounds, rather than on recorded interictal abnormalities, the latter are of critical importance in confirmation and localization. For this reason it becomes important to sort out wicket spikes from other temporal lobe spikes: proper differentiation is a prerequisite for adequate interpretation and for unbiased management and treatment of patients referred to an EEG laboratory.

\section{ACKNOWLEDGMENT}

We are indebted to Doctor Louis Munan, Director, Department of Epidemiology, Centre Hospitalier Universitaire, Sherbrooke, for statistical analysis of the data; and to Diane Lecuyer, Clermont Bolduc and Olivier Gaulin for technical assistance.

\section{REFERENCES}

GIBBS F. A. and GIBBS E. L. (1952). Atlas of Electroencephalography Vol. 2, Ed. 2, Cambridge, Massachusetts, AddisonWesley Press Inc. 442 p.

GIBBS F. A., RICH C. L., and GIBBS, E. L. (1963). Psychomotor Variant Type of Seizure Discharge. Neurology, Vol. 13, No. 12, pp. 991-998.

LOMBROSO C. T. (1967). Sylvian Seizures and Midtemporal Spike in Children. Archives of Neurology, Vol. 17, pp. 52-59.

REIHER J. and KLASS D. W. (1968). Two Common EEG Patterns of Doubtful Clinical Significance. Medical Clinics of North America, Vol. 52, No. 4, pp. 993-940.

For figures 5 to 8 please turn page 


\section{MCKET SPIKES}

Vs

\section{$6 \mathrm{C} / \mathrm{S}$ POSIIVE STMES}

WICKET SPIKES

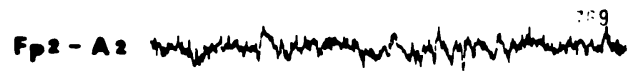

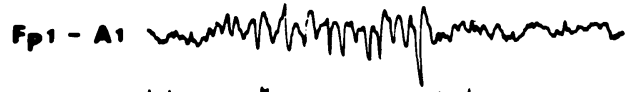

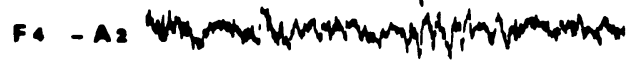

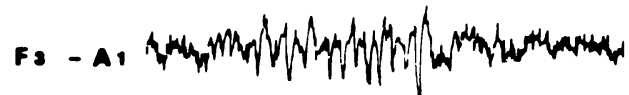

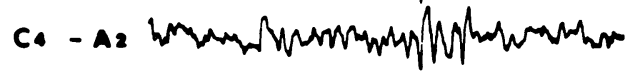

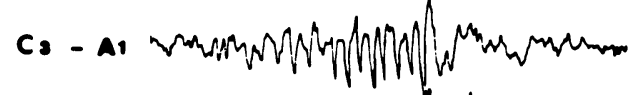

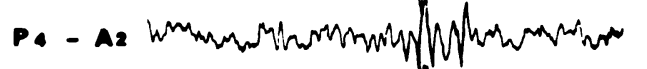

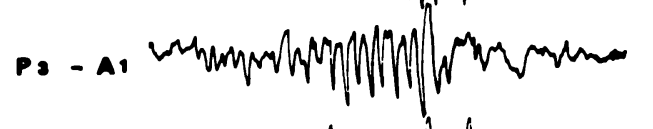

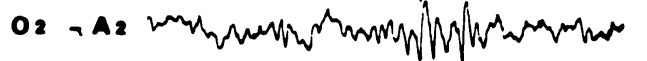

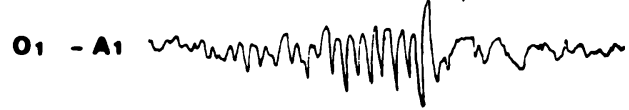

F. - As

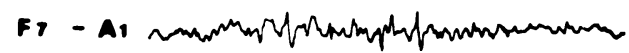

I4 - A2

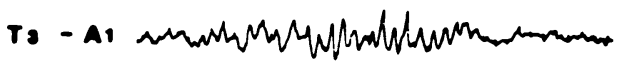

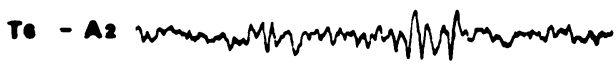

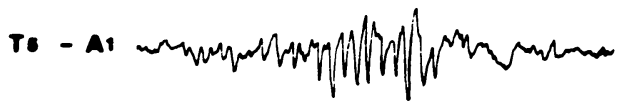

6c/s POSTINE SPIKES

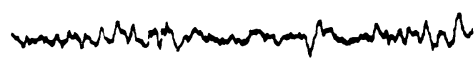

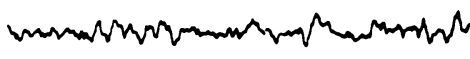

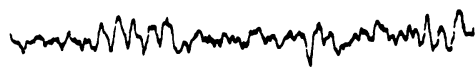

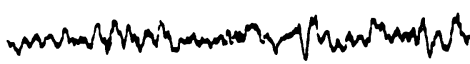

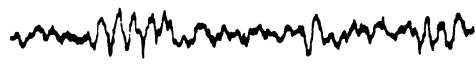

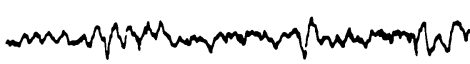

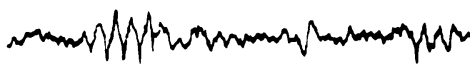

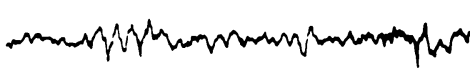

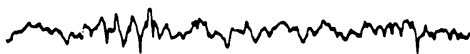

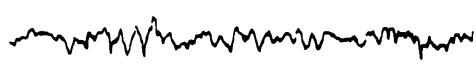

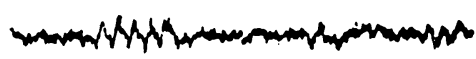

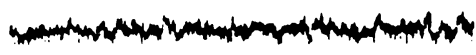

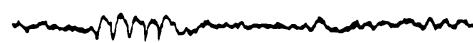

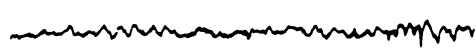

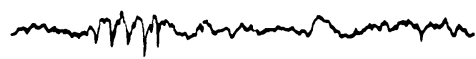

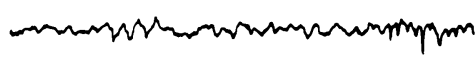

$\left[\circ \log ^{2}\right.$

Figure 5-6 per second positive spikes (right half of the figure) are of lesser amplitude, more regular in frequency, and more posteriorly distributed than the 6-7 per second wicket spikes (left half of the figure). 


\section{WICKET SPIKES \\ Vs \\ rronomoron varuxt}

PSYCHOMOTOR VARIANT

769

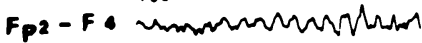

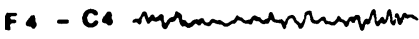

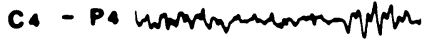

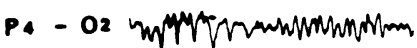

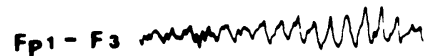

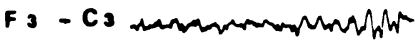

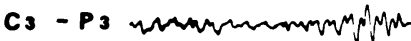

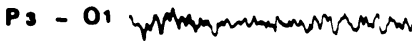

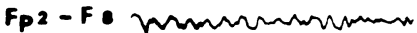

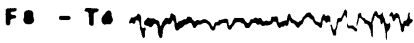

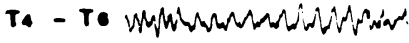

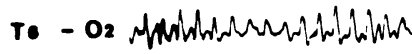

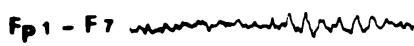

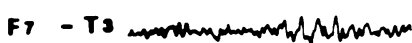

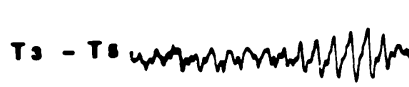

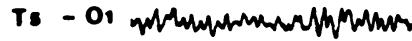

WICKET SPIKES

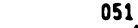

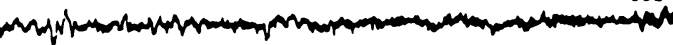

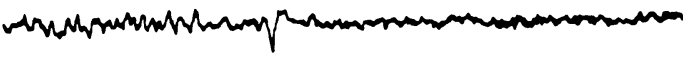

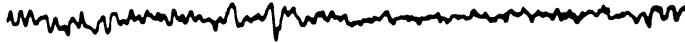

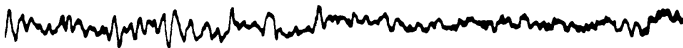

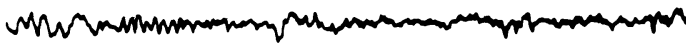

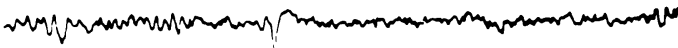

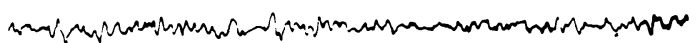

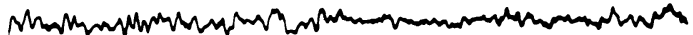

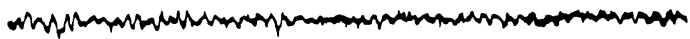

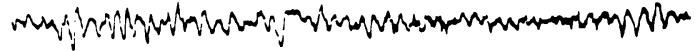

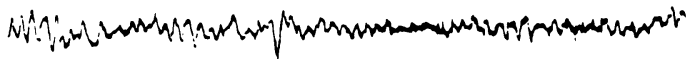

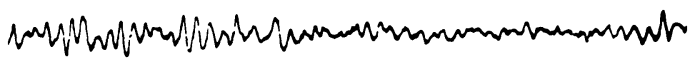

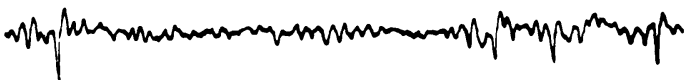

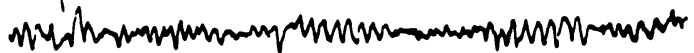

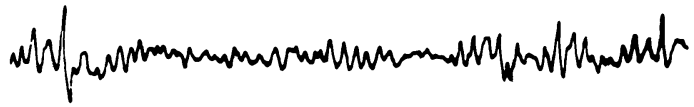

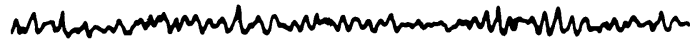

I 1506

Figure 6-Bitemporal psychomotor variant discharges, and bitemporal wicket spikes; note a greater variation in amplitude and frequency, and a lesser spread of wicket spikes to parasagittal regions. 


\section{MCKET SPIKES \\ Vi \\ Mook TEMPORAL Serkes}

WICKET SPKES

124

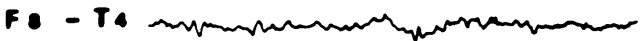

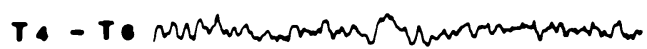

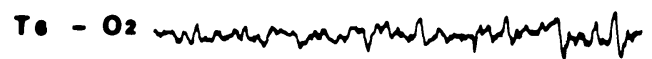

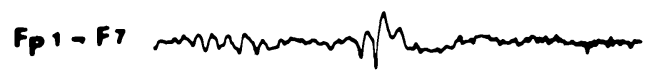

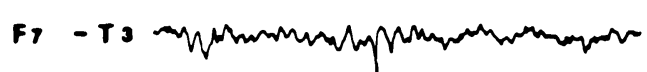

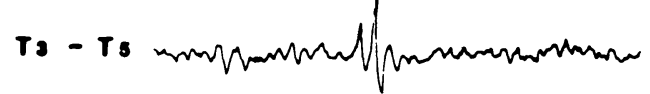

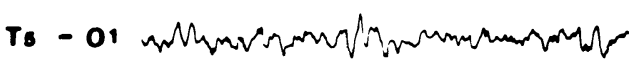

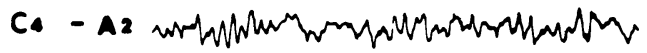

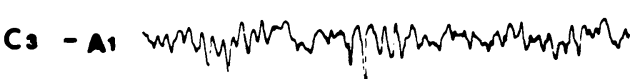

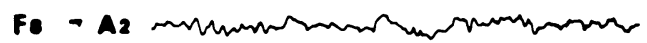

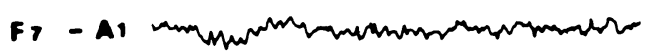

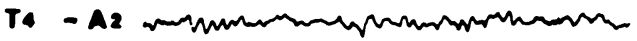

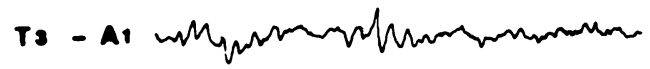

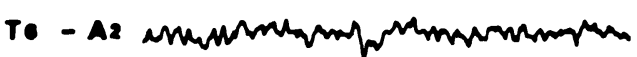

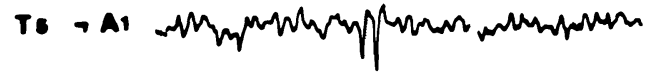

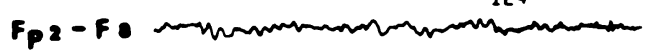

MIDDLE TEMPORAL, SPKES
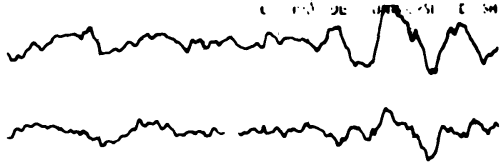

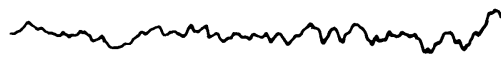

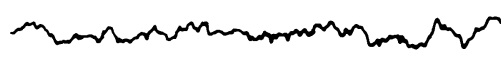

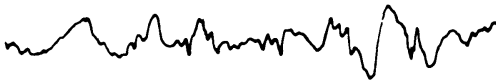

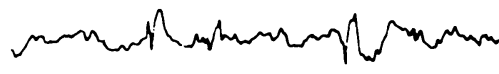

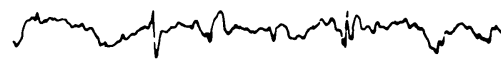

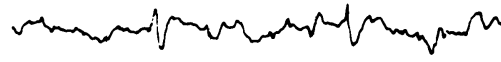

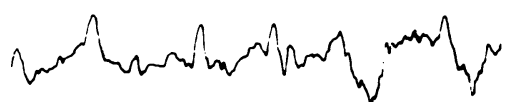

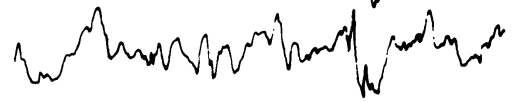

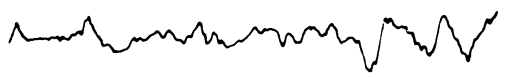

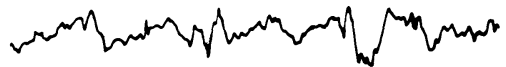

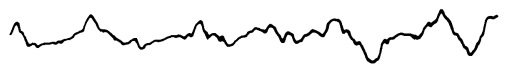

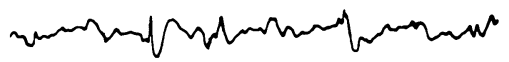

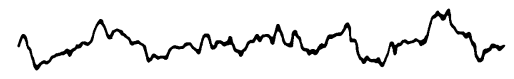

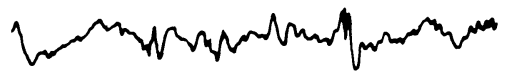

loonv

1006

Figure 7-Middle temporal wicket spikes (on the left) and middle temporal spikes (on the right). Note some similarities in distribution, amplitude and polarity. 


\section{MCKET SPIKES

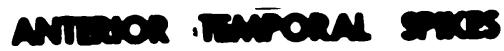

\section{WICKET SPIKES}

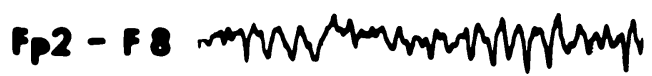

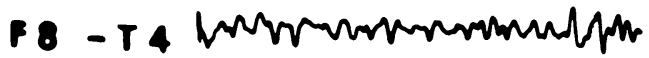

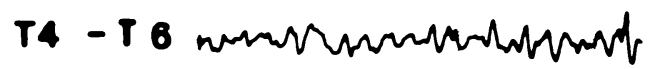

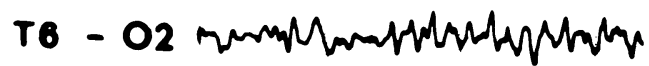

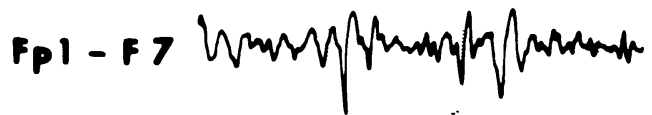

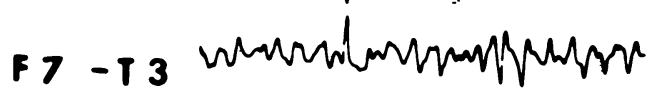

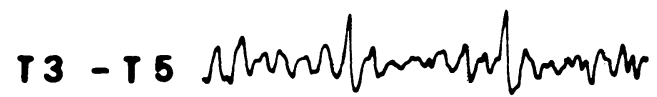

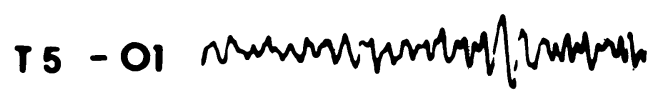

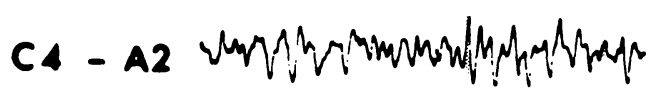

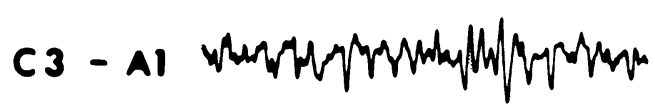

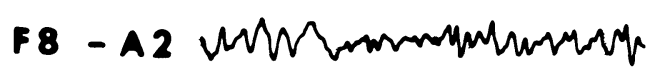

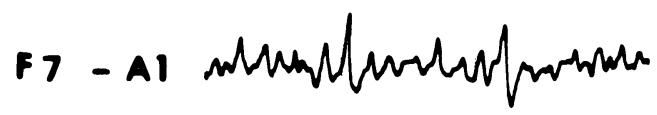

T4 - 12 unkmumbrymoundh

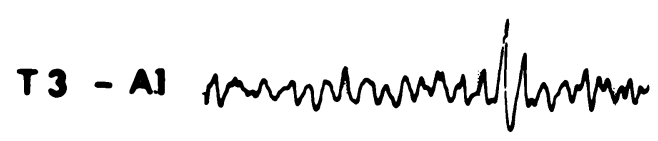

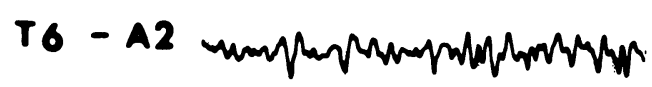

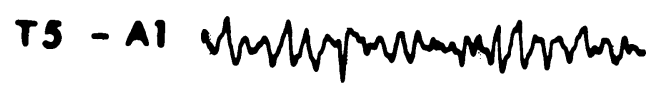

ANTERIOR TEMPORAL SPIKES
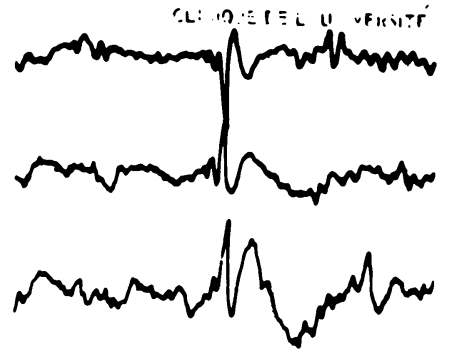

moneryorymors
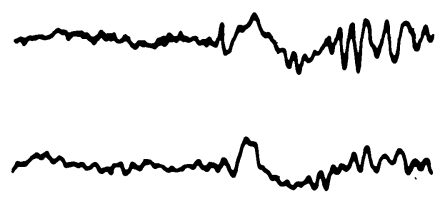

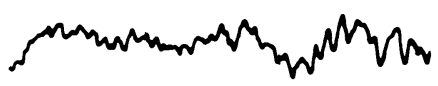

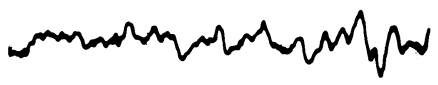

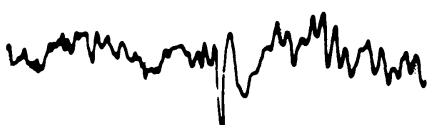

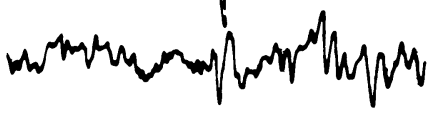

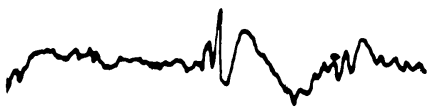

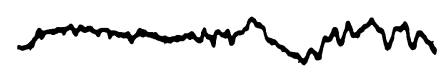

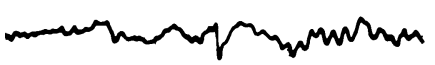

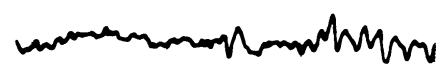

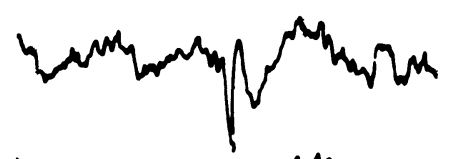

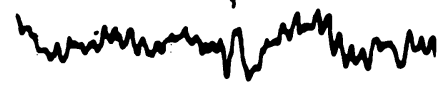

Figure 8-An anterior temporal wicket spike (first spike on the left) and an anterior temporal spike (on the right).

\section{Jour}

